\title{
Early Warning Evaluation of Ecological Security in the Three Gorges reservoir area, China
}

\author{
ZENG YiXiao ${ }^{1}$ GUAN DongJie ${ }^{1,2}$ a ZHANG MengJie $^{1}$ and ZHOU Jian ${ }^{1}$ \\ ${ }^{1}$ College of Architecture and Urban Planning, Chongqing Jiaotong University, No.66 Xuefu Rd., \\ Nan'an Dist., Chongqing 400074, China \\ ${ }^{2}$ Key Laboratory of New Technology for Construction of Cities in Mountain Area, Chongqing \\ University, No.174 ShaZheng Rd., Shapingba Dist.,Chongqing 400030, China
}

a Correspondence:guandongjie_2000@163.com

\begin{abstract}
Keywords: Three Gorges reservoir area; early warning; ecological security
Abstract. According to the characteristics of Three Gorges reservoir ecosystem in Chongqing of China, the index for potential capacity of ecological environment is amended for early warning evaluating the ecological security in 22 counties of the Three Gorges reservoir. Capacity of ecological environment was ranked into five levels, e.g., urgent warning, heavy warning, middle warning, light warning, and no warning. The results demonstrated that the development situation of ecological security in the Three Gorges reservoir was not balanced; meanwhile, there remained the serious ecological deterioration in some regions, indicating that the polarization phenomenon was greatly serious our results suggest that some applicable strategies should be proposed for optimized development.
\end{abstract}

\section{Introduction}

Ecological security is a mixed discipline that combines natural and social sciences. Now there has no well-acknowledged definition about ecological security worldwide. Ecological security also called environment security has two explanations in broad and narrow senses. American International Institute for Applied Systems Analysis advanced the definition of ecological security in a broad sense, which states that Ecological security is a kind of status that people is not threatened in aspects of life, health, happiness, basic right, sources of livelihood, necessary resources, social order, and the adaptation ability to environment change. It's a comprehensive system of artificial ecological security, composed of natural ecological security, economy ecological security, and social ecological security. The definition in a narrow sense means security of natural and semi-natural ecological system, namely, an overall reflection of ecological system integrity and health level. The research on the assessment of ecological security mainly focuses on three aspects: (1) construction of evaluation index system, OEDC first proposed a model of "pressure- state- response" (P-S-R), which can reflect natural environment condition. Don Fallis used the P-S-R model to perceive the scoring rules of risk ${ }^{[1]}$. Li et al studied the relationship between ecological pressure, state and response, and then assessed ecological security condition and development trends, so that necessary requirement were deduced to improve the ecological security in Changdao County, Shandong Province ${ }^{[2]}$; (2) determination of evaluation index value, for example, Takuro Uehara pointed out that the ecological economic threshold may be ahead of the ecological threshold ${ }^{[3]}$. Li took Chongming Island in Shanghai as a case and determined the thresholds of ecological security indicators ${ }^{[4]}$; (3) methods of ecological security assessment, most of the methods mainly choose some characteristic biological, physical and chemical indicators which are sensitive to environmental changes to monitor their feedback against environment change and to judge whether the ecological environment is safe or not.

Till now, scientists have paid more attention to ecological security issues in special regions. Specially, influencing factors of ecological security, as well as damage to ecological system and society, are of very strong concern. Therefore, assessment of ecological security is needed to achieve regional sustainable development. 


\section{Methodology}

Measures of the ecological environment quality and potential need to consider the humanities and natural factors. In this paper, the development and sensitivity degree will be as method to calculate the effect between people and geographical environment. Urbanization rate is expressed as the development degree and the percentage of under primary school education people is expressed as sensitivity degree which is lack of natural succession of knowledge. For the selection of natural factors, land type and contaminated area are measured. The land types are divided by altitude using the environmental factors. Environmental pollution area will be divided into the main city, the core of reservoir, the venter of reservoir and the tail of reservoir based on the geographical characteristics of the Three Gorges Reservoir. As the access to each pollution factor, this article by means of the river pollution concentrations of pollutants in Chongqing to calculate the pollution load and reduce the corresponding multiples.

Through the above analysis, natural complexes features formed by small-scale features of geological landforms, climate, soils, hydrology and vegetation are considered as well as the impact of human activities. The formula for calculating environmental potential of Three Gorges Reservoir $E$ is followed:

$$
E=\frac{U P+D N}{2} \times\left(\sum_{i=1}^{r} A_{i} K_{f i}+\sum_{j=1}^{s} B_{j} K_{v j}\right)
$$

Where, $U P$ represent Urbanization rate (represent the development); DN represent The percentage of illiterate population (reflecting the lack of sensitivity to the natural succession); $K_{f}$ represent Land type factor (reflecting the vulnerability of the natural environment); $K_{v}$ Contamination factor (reflecting the degree of contamination); $r$ represent the number of the type, $i$ represent the land type; $s$ represent environmental pollution area; $j$ represent the environmental pollution areaj; $A_{r}$ and $B_{j}$ are the weight of various land types and the area of each evaluation zone.

The classification and assignment of environmental factors ${ }^{[22,30]}$ are shown in Table 1.

Table 1 Classification of environmental factors $K_{v}, K_{f}$ and the assignment

\begin{tabular}{llllll}
\hline $\begin{array}{l}\text { The assessment districts of } \\
\text { environmental pollution }\end{array}$ & $j$ & $K_{v}$ & The type of land & $i$ & $K_{f}$ \\
\hline The city of basic & 1 & 0.3 & The valley of the river & 1 & 0.8 \\
The core of reservoir & 2 & 0.6 & The hilly area & 2 & 0.7 \\
The venter of reservoir & 3 & 0.8 & The low mountains & 3 & 0.5 \\
The tail of reservoir & 4 & 0.2 & The high mountains & 4 & 0.4 \\
\hline
\end{tabular}

The value of $\frac{U P+D N}{2}$ is between 0 and 1, while the maximum value of $\left(\sum_{i=1}^{r} A_{i} K_{f i}+\sum_{j=1}^{s} B_{j} K_{v j}\right)$ is 2.When greater than 1, it will increase the severity of the former. Therefore, set forth herein: If E> 1, indicating the quality of the environment has reached the degree of risk, if $E>0.5$, showing ecological environment has become deteriorating. The smaller the value of $\mathrm{E}$, the more environments are secure. The greater environmental potential capacity, the bigger human activity is withstood ${ }^{[22]}$.

\section{Results and Discussions}

There are 22 districts and counties in the Three Gorges Reservoir of Chongqing. $U P, D N, K_{f}$ and $K_{v}$ of 22 districts and counties are calculated based on pre-warning model of ecological security. Distribution curve is shown in Fig.1. Distribution curve by above knowable, a percentage of the districts and counties of the urban population $U P$ concentration between $25 \% \sim 25 \%$, individual counties reached $100 \%$, in the urbanization level is higher, belongs to the fast development areas. 


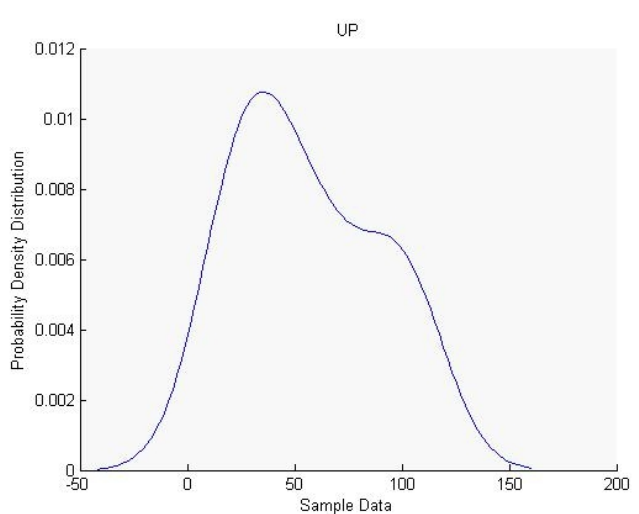

a

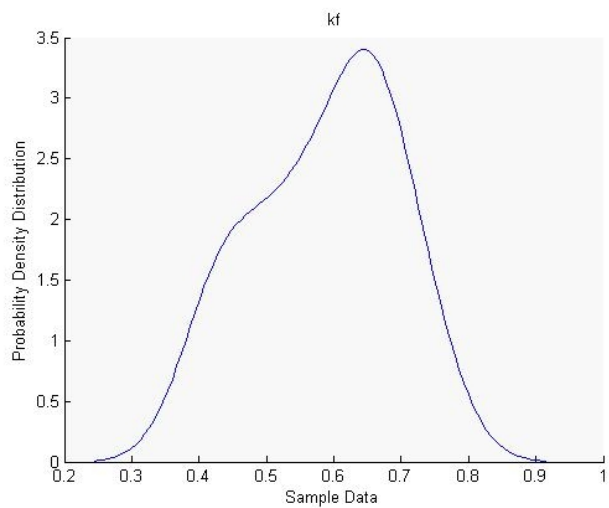

c

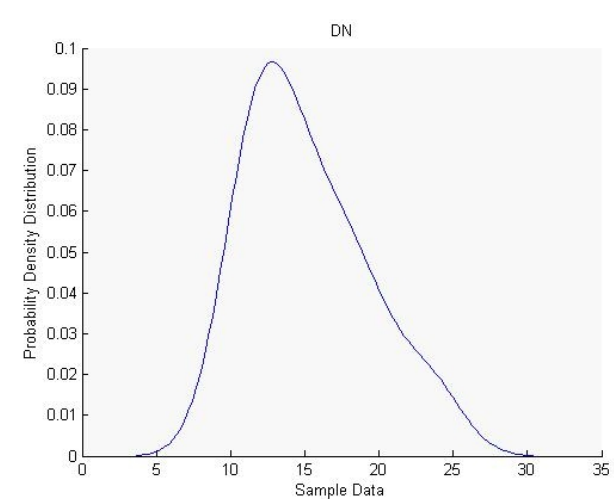

b

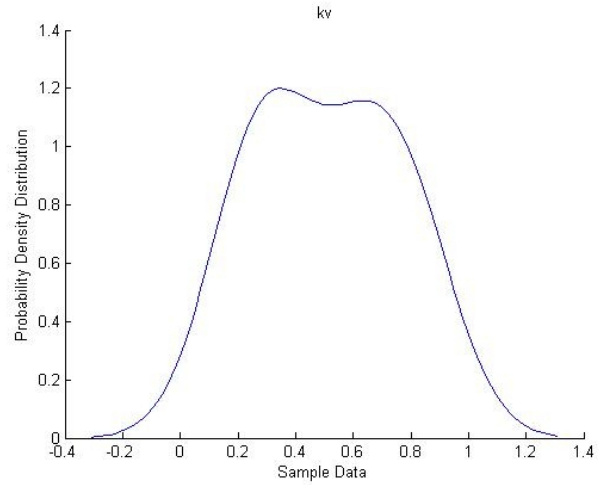

d

Fig.1 $U P, D N$ and the distribution curve of weighted $K_{f}$ and $K_{v}$

The purpose of ecological environment potential assessment is to monitor the state of regional environment, which warning studies can sensitively reflect the abnormal state of alert objects in operation and timely feedback to control. Pre-warning is measuring the spatial temporal scales of normal state and the degree of harm though a certain element's status and future to propose preventive measures. Over the last decade the thinking of pre-warning has been widely used and emergence a large number of studies. Therefore, based on the actual situation of Chongqing Three Gorges reservoir, this paper refers to researches of other areas abroad comprehensively and the results of environmental potential capacity above to grade. As 22 counties for example, the research divide them into warning grading standards of ecological environment.

Table 2 grading standards of ecological environment pre-warning

\begin{tabular}{ccccl}
\hline $\begin{array}{c}\text { The range of } \\
\mathrm{E}\end{array}$ & $\begin{array}{c}\text { The grade of } \\
\text { police }\end{array}$ & $\begin{array}{c}\text { The level of } \\
\text { environmental quality }\end{array}$ & $\begin{array}{c}\text { The color of } \\
\text { LED }\end{array}$ & \multicolumn{1}{c}{ Description } \\
\hline$<0.2$ & V & Urgent warning & Black & $\begin{array}{l}\text { On the brink, the situation is urgent, } \\
\text { need to be dealt with promptly } \\
\text { Severely damage, functional }\end{array}$ \\
$0.2 \sim 0.3$ & IV & Heavy warning & Red & $\begin{array}{l}\text { Begradation, need to take measures } \\
\text { Destroyed trend, still run, need } \\
\text { partial adjustment }\end{array}$ \\
$0.3 \sim 0.4$ & III & Middle warning & Blue & Yamaged sign, not serious, control \\
can be restored
\end{tabular}

In order to analyze the spatial distribution of the evaluation results more clearly, this paper classified the evaluate results based on ArcGIS technology. Three Gorges Reservoir pre-warning distribution is obtained, seen from Figure 2. 


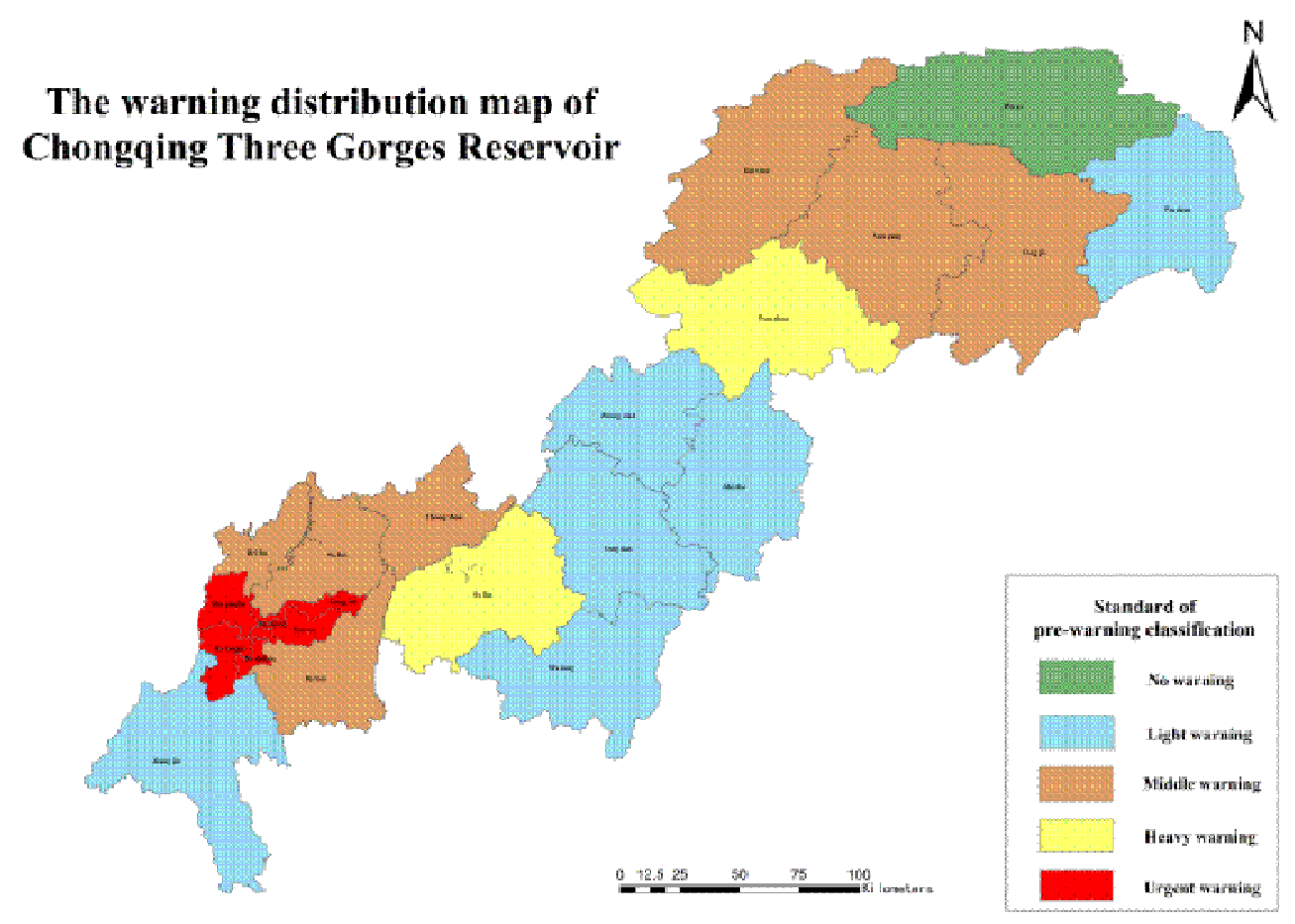

Fig. 2 The pre-warning distribution map of Three Gorges Reservoir

\section{Conclusions}

This paper uses eco-environment potential capacity to evaluate warning level of ecological security in the Chongqing Three Gorges Reservoir. The method has some advantages in elucidating the ecological security. The results demonstrate that the ecological security in the reservoir area has been emerging an increasing trend, but still in a relatively sensitive period. The early warning evaluation using eco-environment potential capacity can provide a study example for the relevant researches. The results can be beneficial to the policy-making. In the further work, establishment of model needs more improvement, and the determination of index system and index weight needs more consideration.

\section{Acknowledgements}

This work is partially supported by Late Project of National Social Science Foundation in China (No. 16FJY010), National Natural Science Foundation of China (No. 41201546), Basic Science and Advanced Technology Fund of Chongqing Scientific Council in China (No. cstc2017jcyjAX0210).

\section{References}

[1] D. Fallis: Attitudes Toward Epistemic Risk and the Value of Experiments. Studia Logica, Vol.86 (2007): p.215-246.

[2] Z. Li, L. Liu, Y. Sun: Assessment method of regional ecological security based on Pressure-State-Response model. Acta Ecologica Sinica, Vol.30(2010), p.6495-6503.

[3] U. Takuro: Ecological threshold and ecological economic threshold: Implications from an ecological economic model with adaptation. Ecological Economics, 2013,Vol.93 (2013), P.374-384.

[4] H. Li, Y. Cai: The threshold of eco-security based on system dynamics and application a case study of Chong ming Island. Acta Ecologica Sinica, Vol.30(2010), P.3661-3662. 